\title{
MicroR-146 protects against rat ischemia-reperfusion injury by targeting NF-kB-mediated PI3K/AKT/mTOR signaling pathway
}

\author{
Leyuan WANG ${ }^{1}$, Guofang $\mathrm{LIU}^{2}$, Zetao SHAO ${ }^{1}$, Qianqian $\mathrm{ZHANG}^{1}$, Lili YIN ${ }^{1}$, Enbo XU ${ }^{1}$, Biao $\mathrm{LI}^{1}$, Xiangxing CUI ${ }^{1}$, \\ Hongtao $\mathrm{TENG}^{3 *}$
}

\begin{abstract}
MicroR-146 (miR-146) plays crucial roles in attenuating nerve injury during cerebral ischemia-reperfusion (I/R) injury. The purpose of this study was to investigate the neuroprotective effect of miR-146 against cerebral I/R injury. Rat model of cerebral I/R injury was established using 4-vessel occlusion and reperfusion. In this study, miR-146 expression was significantly decreased in neurons in cerebral I/R injury rat compared to sham group. In addition, miR-146+/+ significantly decreased inflammatory cytokines, oxidative stress, neuron cell apoptosis and the infarct size in cerebral I/R injury rats $(\mathrm{p}<0.05)$. Transfection of miR-146 reduced apoptosis, autophagy and autophagy-related proteins LC-3, Beclin-1 and increased p62 in the neuron cells compared to control group. Furthermore, overexpression of miR-146 was indicated to directly targeting NF- $\mathrm{kB}$ and activating PI3K/AKT/ mTOR expression in neuron cells. In conclusion, these findings suggested that miR-146 could protect against rat ischemiareperfusion injury by targeting NF- $\mathrm{KB}$-mediated PI3K/AKT/mTOR signaling pathway, which offered a potential molecular for the treatment of cerebral I/R injury.

Keywords: miR-146; cerebral I/R injury; apoptosis; PI3K/AKT/mTOR.

Practical Application: The purpose of this study was to investigate the neuroprotective effect of miR-146 against cerebral I/R injury. Rat model of cerebral I/R injury was established using 4-vessel occlusion and reperfusion. In this study, miR-146 expression was significantly decreased in neurons in cerebral I/R injury rat compared to sham group. In addition, miR-146+/+ significantly decreased inflammatory cytokines, oxidative stress, neuron cell apoptosis and the infarct size in cerebral I/R injury rats $(\mathrm{p}<0.05)$. Transfection of miR-146 reduced apoptosis, autophagy and autophagy-related proteins LC-3, Beclin-1 and increased $\mathrm{p} 62$ in the neuron cells compared to control group. In conclusion, these findings suggested that miR-146 could protect against rat ischemia-reperfusion injury by targeting NF- $\mathrm{KB}$-mediated PI3K/AKT/mTOR signaling pathway, which offered a potential molecular for the treatment of cerebral I/R injury.
\end{abstract}

\section{Introduction}

Cerebral ischemia-reperfusion (I/R) injury is associated with a high incidence of morbidity and mortality (Yang et al., 2013). Clinical data indicate that global cerebral ischemia is a leading cause of mortality worldwide (Müller, et al., 2017; Von der Brelie et al., 2017; Aldakkan et al., 2017). Several mechanisms involve in the pathology of cerebral ischemia reperfusion damage including inflammation, cytotoxicity, oxidative stress, apoptosis and excitotoxicity (Gabriel-Salazar et al., 2018; Liu et al., 2018b; Pala et al., 2019). Cerebral I/R injury frequently injuries the functional area of brain in the hippocampal CA1 pyramidal layer, which further leads to disorder of central nervous system and homeostasis (Jia et al., 2014). Many studies demonstrate that microRNAs are implicated in the pathological processes of cerebral I/R injury, and involve in neuroprotection against ischemia and apoptosis in the pathogenesis of cerebral I/R injury.

MicroRNAs are a class of small endogenous $\sim 21 \mathrm{nt}$ noncoding single-stranded RNAs, which can regulate gene expression at a transcriptional and/or post-transcriptional level by indirect or direct regulation of transcription factors (Yang et al., 2009; Glinsky, 2009; Li et al., 2009; Chang \& Mendell, 2007). Previously, several studies have indicated that microRNAs expression levels are significantly changed in cerebral I/R injury, which emphasizes the implication of microRNAs in pathological processes (Yao et al., 2018; Liang et al., 2018; Tao et al., 2015). Dysfunction of the microRNA network has been regarded as a major regulator in cerebral I/R injury (Pan et al., 2017). MicroRNAs molecules have been predicted or identified by regulating autophagy-related LC-3 and Beclin-1 proteins during cerebral I/R injury (Hu \& Shen, 2019). However, there is limited understanding regarding the potential mechanism mediated by microRNAs in cerebral I/R injury.

Currently, inhibition of NF- $\mathrm{kB}$ signaling pathway reduces expression of inflammatory cytokines during brain I/R injury, which further leads to improvement of infarct size, neurological 
outcomes, and cerebral I/R injury (Du et al., 2019). In addition, up-regulation of PI3K/AKT/mTOR signaling pathway suppresses apoptosis and inhibits autophagy in oxygen glucose deprivation/ reoxygenation injury (Yang et al., 2018). Furthermore, given that the importance of miR-146 role in I/R injury, microR-146 (miR-146) may regulate apoptosis and improve injury in $\mathrm{I} / \mathrm{R}$ injury (Huang et al., 2018). The purpose of this study was to investigate the possible role and underlying mechanism of miR-146 in cerebral I/R-induced neuronal apoptosis. Cerebral $\mathrm{I} / \mathrm{R}$ rat model were established and we investigated the role of miR-146 in in the hippocampal CA1 pyramidal layer. Moreover, we confirmed that the change of NF- $\mathrm{KB}$-mediated PI3K/AKT/ mTOR signaling pathway in the hippocampal CA1 pyramidal layer in the cerebral I/R injury rat. This study also performed tests to evaluate inflammatory cytokines concentration to confirm the role of miR-146 in cerebral I/R injury rat.

\section{Materials and methods}

\subsection{Cerebral I/R rat model}

Cerebral I/R mice model was established using the four-vessel occlusion (4-VO) method as described previously (Huang et al., 2019). Briefly, a total of 32 miR-146 knock in (miR-146+/+) and B6 (wild-type, $\mathrm{n}=16$ ) mice (8 weeks old, $32 \pm 5$ g body weight) were purchased from the Experimental Animal Central of Shandong University. All animals were housed under a $12 \mathrm{~h} \mathrm{light/dark}$ cycle, $23-25^{\circ} \mathrm{C}, 55 \pm 10 \%$ humidity and freely accessed to standard food and tap water. All mice were fasted for $12 \mathrm{~h}$ with water ad libitum before the surgery. The animals were incised in the midline of the neck, and the right common carotid artery was bifurcated into the external carotid artery and the internal carotid artery. An intraluminal filament (Doccol Corporation, Sharon, USA) was inserted into the internal carotid artery. The filament was used to block the right middle cerebral artery. The filament was withdrawn to allow middle cerebral artery reperfusion after $2 \mathrm{~h}$ operation. Successful occlusion was identified by evaluating the cerebral blood flow using laser Doppler flowmetry (ADInstruments, Dunedin, New Zealand). The sham-operated miR-146+/+ mice underwent anesthesia and vertebral artery occlusion without the common carotid arteries occlusion. Rats were divided into three groups: I/R group, miR-146+/+ group, and sham group. All operative procedures were approved by the Institutional Animal Care and Use Committee of Fourth people's hospital of Shandong jinan, China.

\subsection{Enzyme-Linked Immuno Sorbent Assay (ELISA)}

Blood samples were obtained from experimental animals and serum was isolated using centrifugation at $12,000 \mathrm{xg}$ for 10 min at $4{ }^{\circ} \mathrm{C}$. Serum levels of IL1 $\beta$ (RLB00), TNFa (RTA00) and IL6 (R6000B) were evaluated using a commercial ELISA (R\&D system) according to the manufacturer's instructions.

\subsection{Assessment of MDA}

A commercial chemical colorimetrical assay kit (MDA/ UA/vitamin C/vitamin E Detection Kit; Nanjing Jiancheng
Bioengineering Institute, Nanjing, China) was used to measure MDA levels in serum according to the manufacturer's instructions. Quality of MDA was determined using a spectrophotometer (Genesys 10 UV Scanning UV/VIS Spectrophotometer; Shimadzu, Tokyo, Japan). The concentration of MDA was expressed as $\mu \mathrm{M}$.

\subsection{Measurement of intracellular ROS}

ROS Detection Assay Kit (ab139476, Abcam) was used to analyze the ROS production according to the manufacturer's instructions. In brief, serum sample $(10 \mu \mathrm{L})$ was treated with a ROS scavenger $(5 \mathrm{mM})$ for $1 \mathrm{~h}$ at $37^{\circ} \mathrm{C}$ and washed with PBS three times and then incubated in $100 \mu \mathrm{L}$ of DCFDA $(10 \mu \mathrm{M})$ for $30 \mathrm{~min}$ at $37^{\circ} \mathrm{C}$. Fluorescence was measured using a microplate reader (Fluoroskan Ascent) at $485 \mathrm{~nm}$ excitation and $530 \mathrm{~nm}$ emission.

\subsection{Assessment of SOD activity}

A commercial assay kit SOD Assay Kit (19160-1KT-F, Sigma-Aldrich) was used to measure SOD activity. The activity of SOD in the serum samples was measured according to the manufacturer's instructions. The results were recorded using a microplate reader (Fluoroskan Ascent) at $405 \mathrm{~nm}$.

\subsection{Infarct volume measurement}

The infarct volume was evaluated $24 \mathrm{~h}$ after cerebral I/R rat model establishment. Brain tissue was removed, stored at $-80{ }^{\circ} \mathrm{C}$ for $2 \mathrm{~h}$, cut into coronal sections ( $2 \mathrm{~mm}$ thick), and then incubated in $2 \%$ TTC (SigmaeAldrich, Saint Louis, MO, USA) at $25^{\circ} \mathrm{C}$ for $1 \mathrm{~h}$. Brain sections were fixed using $4 \%$ paraformaldehyde for $12 \mathrm{~h}$ at $25^{\circ} \mathrm{C}$, and captured using light microscope (Olympus, Japan). Image J software (version 4.6) was used to analyze the infarct area in experimental animals.

\subsection{TUNEL staining}

Apoptosis of cells were measured using TdT-mediated dUTP nick-end labeling (TUNEL) staining (Beyotime Biotechnology, Beijing, China) kit. In brief, brain sections were permeabilized by proteinase $\mathrm{K}$ solution $(20 \mathrm{mg} / \mathrm{ml})$ at $25^{\circ} \mathrm{C}$ for $2 \mathrm{~h}$, raised with PBS, and then incubated with terminal deoxynucleotidyl transferase (TdT). Brain sections were added fluorescein at $37^{\circ} \mathrm{C}$ for $1 \mathrm{~h}$ and imaged using a Leica microscope (Leica TCS SP8, Solms, Germany). For neuronal cells, cells $\left(1 \times 10^{6}\right)$ were fixed with $4 \%$ paraformaldehyde for $2 \mathrm{~h}$ at $25^{\circ} \mathrm{C}$, washed with PBS, incubated with TdT and DAPI (5\%) for $2 \mathrm{~h}$ at $25^{\circ} \mathrm{C}$. Images of cells were captured using a Leica microscope (Leica TCS SP8, Solms, Germany). Quantification of TUNEL-positive neurons was imaged using Image-Pro Plus 6.0 (version 3.0).

\subsection{Evaluation of neurological score}

All mice were evaluated using a neurological evaluation instrument as described previously (Garcia et al., 1995). In brief, neurological scoring system was scored as follow: $0-3$, spontaneous activity over a 3-minute period, symmetry of movement, open-field path linearity, or beam walking on a $3 \mathrm{~cm} \times 1 \mathrm{~cm}$ beam; $1-3$ response to vibrissae touch. 


\subsection{Immunofluorescence}

Neuronal cells, cells $\left(1 \times 10^{6}\right)$ were fixed with $4 \%$ paraformaldehyde for $2 \mathrm{~h}$ at $25^{\circ} \mathrm{C}$ Cells were incubated with primary antibody: LC3 $(1: 1,000 ; \mathrm{ab} 48394, \mathrm{Abcam})$ for $12 \mathrm{~h}$ at $4^{\circ} \mathrm{C}$. Cells were incubated with HRP-conjugated goat anti-rabbit IgG (1:2,000; Santa Cruz Biotechnology, SantaCruz, CA, USA) for $12 \mathrm{~h}$ at $4{ }^{\circ} \mathrm{C}$. Cells were then incubated with 3,30-diaminobenzidine (DAB,Sigma, St.Louis,MO,USA). Immunofluorescence followed with appropriate secondary antibodies (AlexaFluor, MolecularProbesInc.) for $2 \mathrm{~h}$ at $25^{\circ} \mathrm{C}$ and counterstained with $5 \%$ DAPI for $1 \mathrm{~h}$ at $25^{\circ} \mathrm{C}$. Mounting medium was added on the slides prior to be covered with cover slips for observation by a laser scanning confocal microscope (LSM880, Zeiss, Jena, Germany).

\subsection{Transient transfection}

The construction of plasmids expressing $N F-\kappa B$ (pcDNA3.1-NF- $\kappa$ B, NF- $\kappa$ B), pcDNA3.1 (Control), miR-146 or miR-negative control (miR-NC) was sythesed by Invitrogen (Invitrogen; Thermo Fisher Scientific, Inc.). Neuronal cells, cells $\left(1 \times 10^{4} /\right.$ well $)$ were cultured in six-well plate and transfected with NF- $\kappa \mathrm{B}$, Control miR-146 or miR-NC at $80 \%$ confluence using Lipofectamine 3000 (Invitrogen; Thermo Fisher Scientific, Inc.) according to the manufacturer's instructions. The cells were cultured for $12 \mathrm{~h}$ at $37^{\circ} \mathrm{C}$ for further analysis.

\subsection{Luciferase reporter assay}

The 3'untranslated region (UTR) of NF- $\kappa \mathrm{B}$ containing the binding sites of miR-146 was cloned into the dual luciferase reporter vector pGL3 (pGL3-NF- $\mathrm{BB}-3^{\prime} \mathrm{UTR}$ ). Cells were cultured in 12 -well plates at $1 \times 10^{5}$ cells/well at $37^{\circ} \mathrm{C}$ for $24 \mathrm{~h}$. After culture, cells were co-transfected with the reporter vector containing either wild-type or mutant 3'UTR of NF- $\kappa B$ along with miR-146 using Lipofectamine 3000 (Invitrogen; Thermo Fisher Scientific, Inc.). Luciferase and Renilla activity was evaluated using the Dual Luciferase Reporter Assay Kit (Promega) after 48 - $\mathrm{h}$ incubation according to the manufacturer's instruction.

\subsection{Cell counting kit (CCK-8) assay}

Neuronal cells were cultured in a $96-$ well plate at $37^{\circ} \mathrm{C}$ in $5 \%$ $\mathrm{CO}_{2}$ for $12 \mathrm{~h}$. Cells were treated with NF- $\kappa$ B inhibitor (NF- $\kappa B I R$, $2 \mathrm{mM}$, Sigma-Aldrich) for $4 \mathrm{~h}$ at $37^{\circ} \mathrm{C}$. Next, CCK-8 $(10 \mu \mathrm{l}$, Dojindo, Tokyo, Japan) was added into each well and cultured for $2 \mathrm{~h}$ at $37^{\circ} \mathrm{C}$. The absorbance at $450 \mathrm{~nm}$ was measured using a microplate reader (Fluoroskan Ascent) at $405 \mathrm{~nm}$.

\subsection{Real-time quantitative PCR (RT-qPCR)}

Total RNA was isolated from neuronal cells $\left(1 \times 10^{7}\right)$ using TRIzol $^{\circledR}$ reagent (Takara, Otsu, Shiga, Japan). Equal RNA samples $(1.0 \mu \mathrm{g})$ were reversetranscribed to cDNA using the PrimeScript RT gDNA Eraser kit (Takara, Otsu, Shiga, Japan) according to manufacturer's instructions. Primers used in this study were as follows: LC3: forward: 5'-AGCAGCATCCAACCAAAATC-3'; reverse, 5'-CTGTGTCCGTTCACCAACAG-3'; Beclin-1, forward: 5' -CAATGGTGGCTTTCCTGGAC-3', reverse, 5'-TGAGAGCTTTTGTCCACTGCT-3'; p62: forward: 5'-GTCAATTTCCTGAAGAATGTGGG-3'; $\beta$-actin: forward: 5-AGATGTGGATCAGCAAGCA-3; reverse, 5-GCGCAAGTTAGGTTTTGTCA-3; reverse, 5'-GAGTTCACCTGTG GATGGGTC-3'; miR-146a-3p (5'-3': CCTGTGAAATTCAGTTCTTCAG). U6 (5'-3': AGAGAAGATTAGCATGGCCCCTG”). Quantitative PCR was performed with SYBR Premix ExTaq TMII (Takara, Otsu, Shiga, Japan) with a help of 7500 real-time PCR System (Applied Biosystems, Foster City, CA, USA). The relative expression of mRNA or miRNA was calculated using $2^{-\Delta \Delta C T}$ method and normalized to the expression of $\beta$-actin or U6, respectively.

\subsection{Western blot analysis}

Neuronal cells ( $1 \times 10^{8}$ ) were lysed using Radio Immunoprecipitation Assay (RIPA, Sigma-Aldrich) buffer and the quality of total proteinswas quantified using the bicinchoninic acid (BCA) protein concentration assay kit (Biyuntian, Beijing, China). Equal amounts of protein $(40 \mu \mathrm{g})$ was separated by $12 \%$ SDS-PAGE gels and transferred to polyvinylidene fluoride (PVDF) membranes (Millipore, Massachusetts, USA). Membranes were blocked with 5\% BSA (Sigma-Aldrich) for $2 \mathrm{~h}$ at room temperature. After washing with PBS, the membranes were incubated with primary antibody, PI3K (sc-423), AKT (sc-293172), mTOR (sc-293172), p-PI3K (sc-7174), p-AKT (sc-33437), p-mTOR (sc-33437), $\beta$-actin (sc-8432) at 1:1,000 dillutions at $4{ }^{\circ} \mathrm{C}$ overnight, followed by secondary antibody (1: 2,000, sc-8196, Santa Cruz Biotechnology) for $2 \mathrm{~h}$ at $25^{\circ} \mathrm{C}$. Finally, the blots were inspected by Emitter Coupled Logic (ECL) substrate (Thermo Scientific, Rockford, IL, USA) on Kodak X-ray films or using a chemiluminescence image analysis system (Tanon 5200). The intensity of the bands was analyzed using Quantity One software version 4.62 (Bio-Rad).

\subsection{Statistical analyses}

All data are expressed as the mean \pm SD of at least three independent experiments. Student's t-test and one-way ANOVA analysis followed by Tukey's test were used for statistical data evaluations. A p value less than 0.05 is considered significant.

\section{Results}

\section{$3.1 \mathrm{miR}-146+/+$ decreases brain damage in cerebral $I / R$ injury rat}

To investigate the role of miR-146 in the cerebral I/R in rats, NSS score and histological analyses were performed in experimental rats. Expression of miR-146 was significantly decreased in hippocampal CA1 pyramidal layer in cerebral I/R injury mice compared to sham group (Figure 1A). Compared with I/R group, miR-146+/+ rats presented higher neurological score. No significant difference was found between miR-146+/+ group and sham group (Figure 1B). miR-146+/+ significantly decreased cell apoptosis in hippocampal CA1 pyramidal layer compared to I/R group (Figure 1C). Compared with I/R group, a significant decreased infarct size of hippocampal CA1 pyramidal layer was shown in miR-146+/+ mice (Figure 1D). 

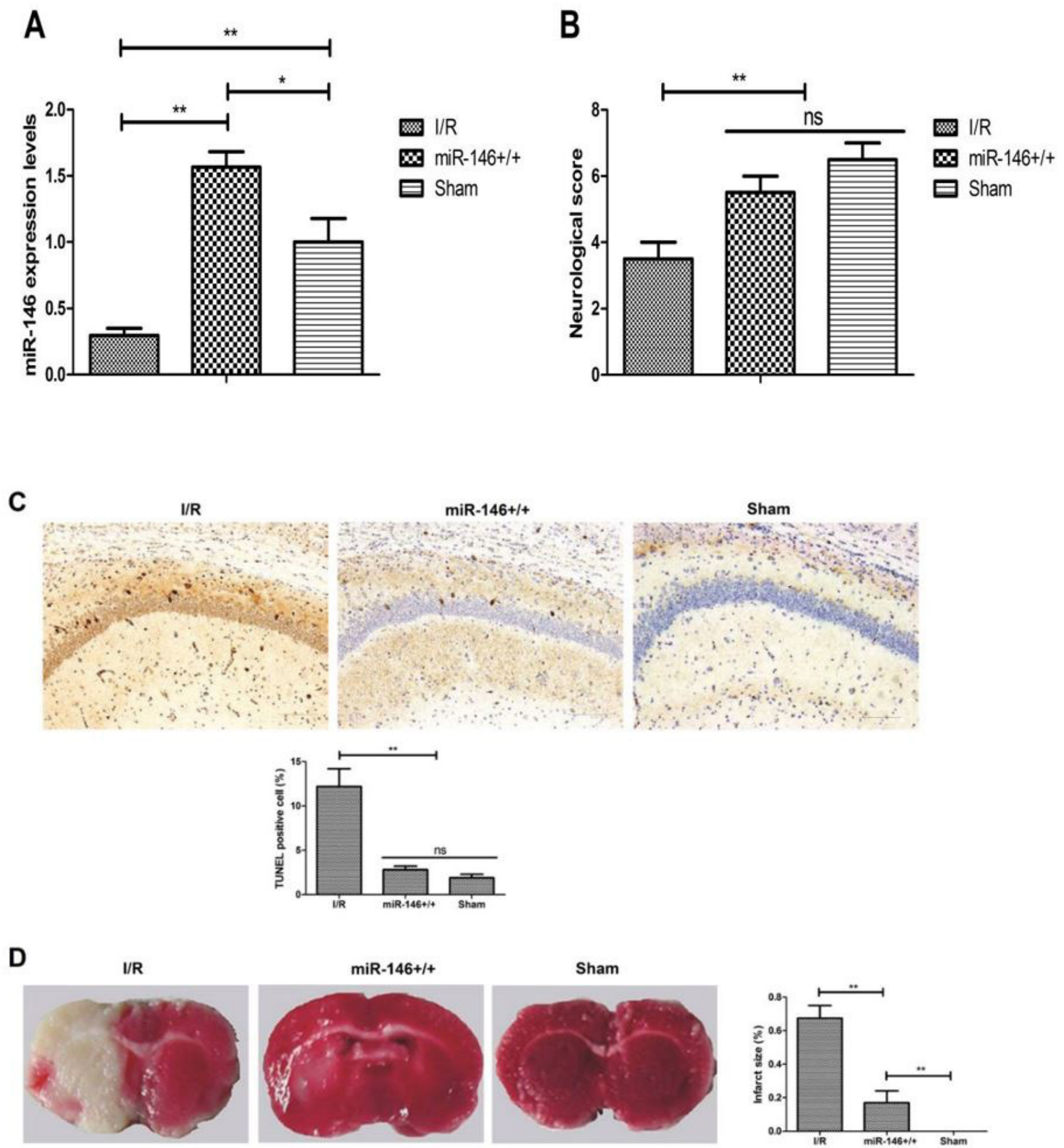

Figure 1. miR-146+/+ decreased brain damage in cerebral I/R injury rat. (A) Expression of miR-146 in hippocampal CA1 pyramidal layer in cerebral I/R, miR-146+/+ and sham group; (B) Neurological score of cerebral I/R, miR-146+/+ and sham group; (C) Apoptosis in hippocampal CA1 pyramidal layer in cerebral I/R, miR-146+/+ and sham group; (D) Infarct size of hippocampal CA1 pyramidal layer in cerebral I/R, miR$146+/+$ and sham group. ${ }^{\star *} \mathrm{P}<0.01$ compared with miR-NC group. $\mathrm{ns} \mathrm{P}>0.05$ compared with miR-NC group.

\section{2 miR-146+/+ down-regulates inflammation and oxidative stress in cerebral I/R injury rat}

The anti-inflammatory and antioxidant effects of miR-146 were investigated in cerebral $\mathrm{I} / \mathrm{R}$ injury rat. A significant decreasing in the levels of serum IL-1 $\beta$, IL- 6 and TNF- $\alpha$ was observed in miR-146+/+ mice compared to I/R group (Figure 2A). Compared with I/R group, miR-146+/+ increased the contents of malondialdehyde (MDA), the activity of superoxide dismutase (SOD) and decreased ROS in serum in I/R injury rat (Figure 2B-D). 
A

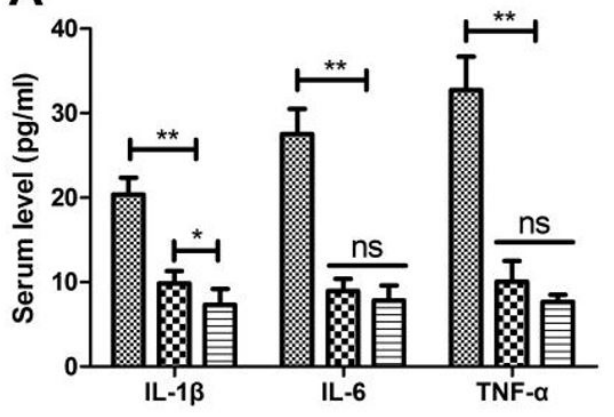

C

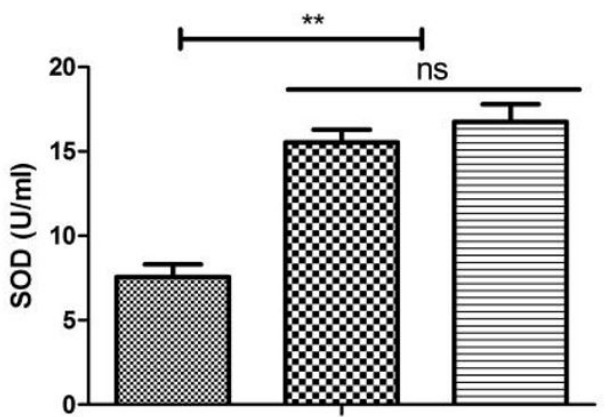

B
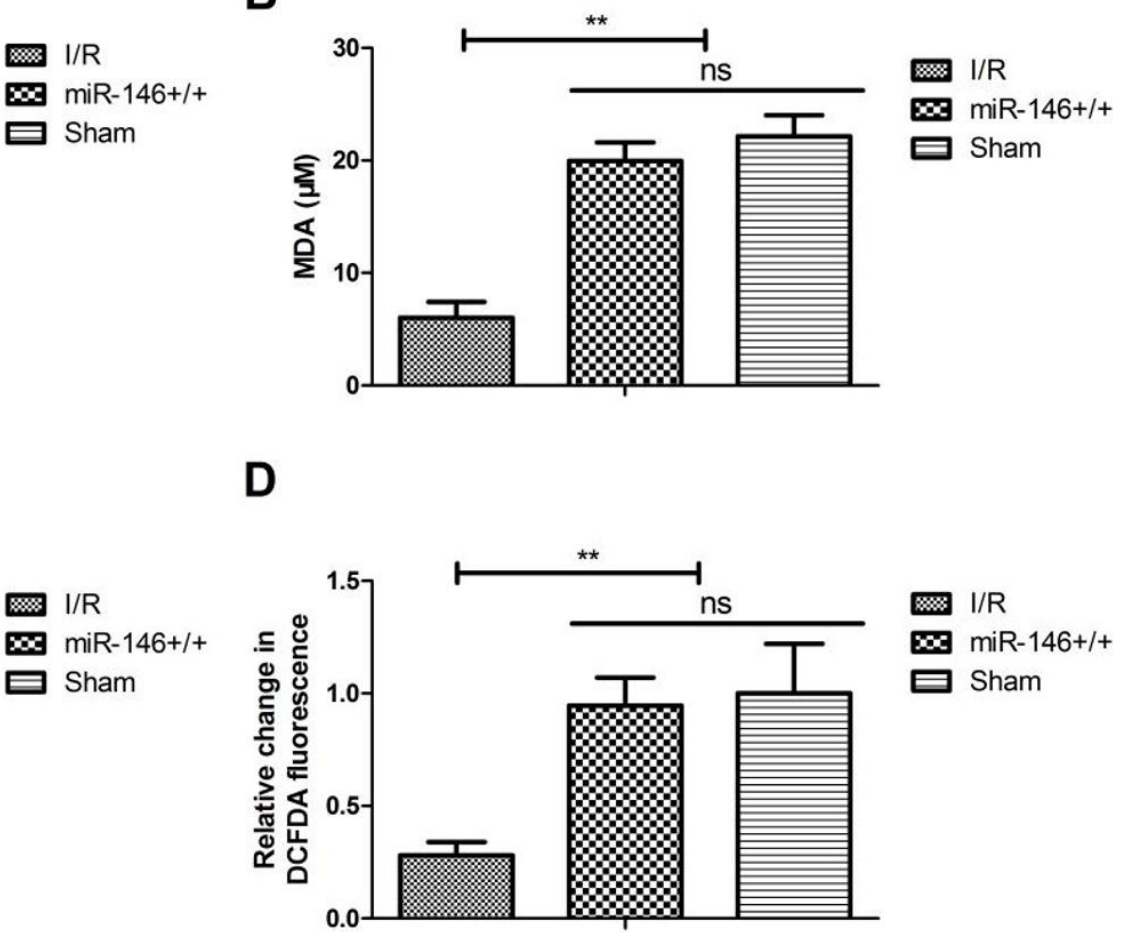

Figure 2. miR-146+/+ down-regulated inflammation and oxidative stress in cerebral I/R injury rat. (A) The levels of serum IL- $1 \beta$, IL- 6 and TNF- $\alpha$ in cerebral I/R, miR-146+/+ and sham group; (B-D) The contents of MDA (B), the activity of SOD (C) and ROS (D) in serum in cerebral I/R, miR-146+/+ and sham group. ${ }^{* *} \mathrm{P}<0.01$ compared with miR-NC group. $\mathrm{nsP}>0.05$ compared with miR-NC group.

\section{3 miR-146 inhibits neuronal cell death and improves neuronal cell survival}

We further investigated the effect of miR-146 transfection on neuronal cell survival. As illustrated in Figure 3A, miR-146 transfection showed significant increasing expression levels of miR-146 in neuronal cells compared to the control miRNA. Transfection of miR-146 significantly improved neuronal cell survival compared to control miRNA (Figure 3B).

\section{4 miR-146 reduces apoptosis and autophagy in neuronal cell}

The apoptosis and autophagy was analyzed in neuronal cell after transfection with miR-146. Transfection of miR-146 inhibited apoptosis of neuronal cells compared to control group (Figure 4A). As shown in Figure 4B, miR-146 reduced autophagy in neuronal cell basing LC3 protein expression. RT-QPCR and Western blot demonstrated that miR-146 decreased autophagy-related gene and proteins LC-3, Beclin-1 and increased p62 in neuronal cells (Figure 4C-D).

\section{5 miR-146 directly modulates $N F-\kappa B$ expression in neuronal cell}

The target molecular of miR-146 was detected in neuronal cells using luciferase reporter assay. The results showed that luciferase activity was reduced by co-transfection with miR-146 mimics carrying the 3'UTR of NF- $\kappa B$ compared with the negative control (Figure 5A). The results of Western blotting showed that miR-146 transfection decreased NF- $\kappa B$ and $p N F-\kappa B$ expression in neuronal cells (Figure 5B). These data indicated that miR-146 transfection directly inhibited the expression of $\mathrm{NF}-\kappa \mathrm{B}$ in neuronal cells.

\section{6 miR-146 activates PI3K/Akt/mTOR signaling pathway by targeting $N F-\kappa B$ gene in neuronal cell}

To further investigate the possible mechanism of miR-146, $\mathrm{PI} 3 \mathrm{~K} / \mathrm{Akt} / \mathrm{mTOR}$ signaling pathway was analyzed in neuronal cells after transfection with miR-146. Transfection with miR-146 increased PI3K, p-PI3K, Akt, p-Akt, mTOR and $\mathrm{p}$-mTOR expression in neuronal cells (Figure $6 \mathrm{~A}$ ). NF- $\kappa \mathrm{B}$ overexpression canceled miR-146-increased (miR-146+NF- $\kappa \mathrm{B}$ ) PI3K, p-PI3K, Akt, p-Akt, mTOR and p-mTOR expression in neuronal cells compared to control (Figure 6A). Treatment with NF- $\kappa \mathrm{B}$ inhibitor (NF- $\kappa \mathrm{BIR}$ ) increased PI3K, Akt and mTOR expression in neuronal cells compared to control (Figure 6B). Overexpression of NF- $\kappa \mathrm{B}$ also abolished miR-146-decreased apoptosis of neuronal cells (Figure 6C). These data indicated that miR-146 activates PI3K/Akt/mTOR signaling pathway by targeting NF- $\kappa \mathrm{B}$ gene in neuronal cell.

\section{Discussion}

MicroRNAs (miRs) have become crucial posttranscriptional regulators of gene expression by regulation of various signal pathways during ischemia reperfusion injury (Lorenzen et al., 2013; Weiss et al., 2012; Zhai et al., 2012). Study has found that miR-146 protects renal function via targeting IGSF1 by activation of PI3K/ AKT (Huang et al., 2018). In this study, we showed that miR-146 
A

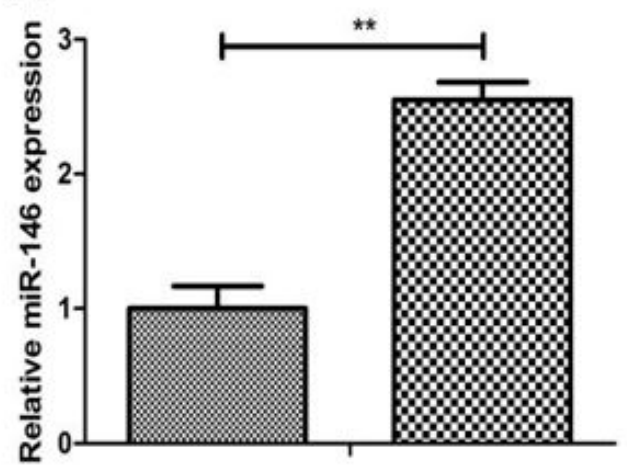

B

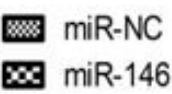

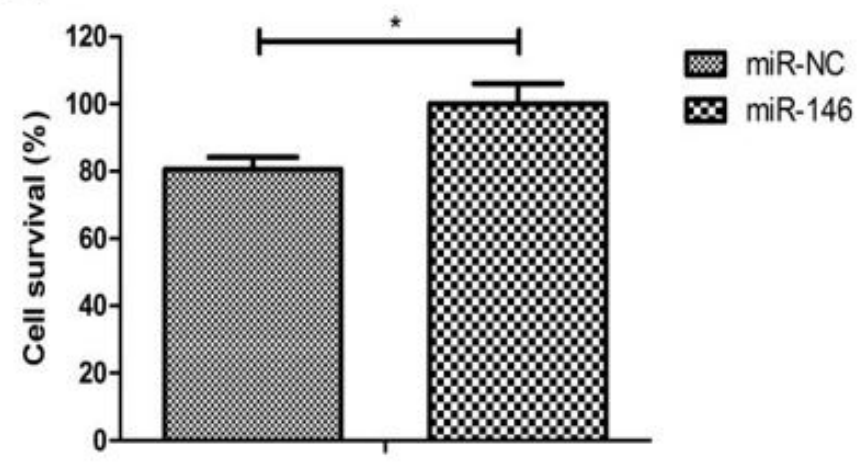

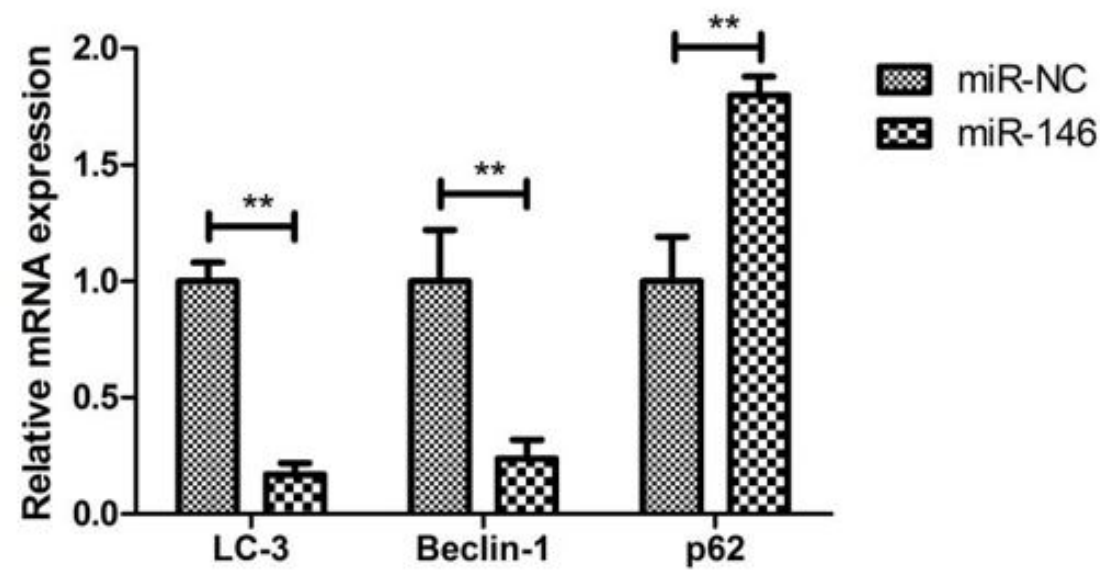

D
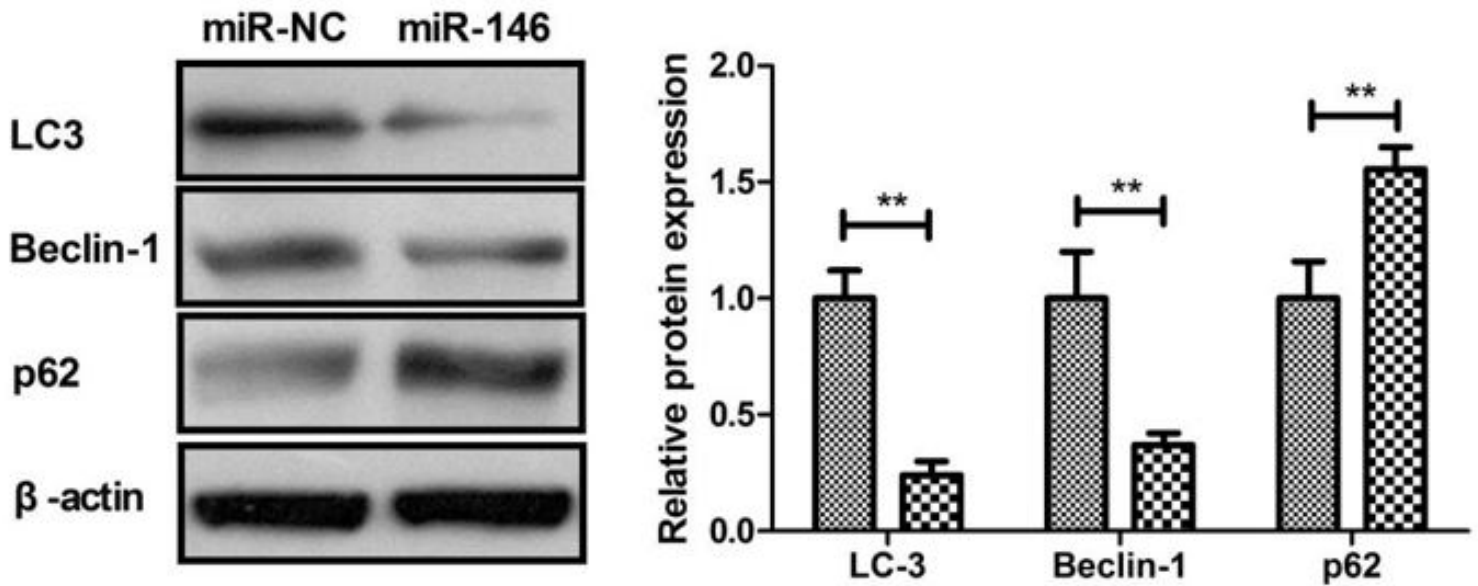

miR-NC miR-146

Figure 3. miR-146 reduced apoptosis and autophagy in neuronal cells. (A) Effects of miR-146 transfection on apoptosis of neuronal cells compared to control group; (B) Transfection of miR-146 reduced autophagy in neuronal cell basing LC3 fluorescence; (C, D) Transfection of miR-146 decreased autophagy-related geneand proteinexpression of LC-3, Beclin- 1 and increased p 62 in neuronal cells. ${ }^{*} \mathrm{P}<0.01$ compared with miR-NC group. nsP $>0.05$ compared with miR-NC group. 
A
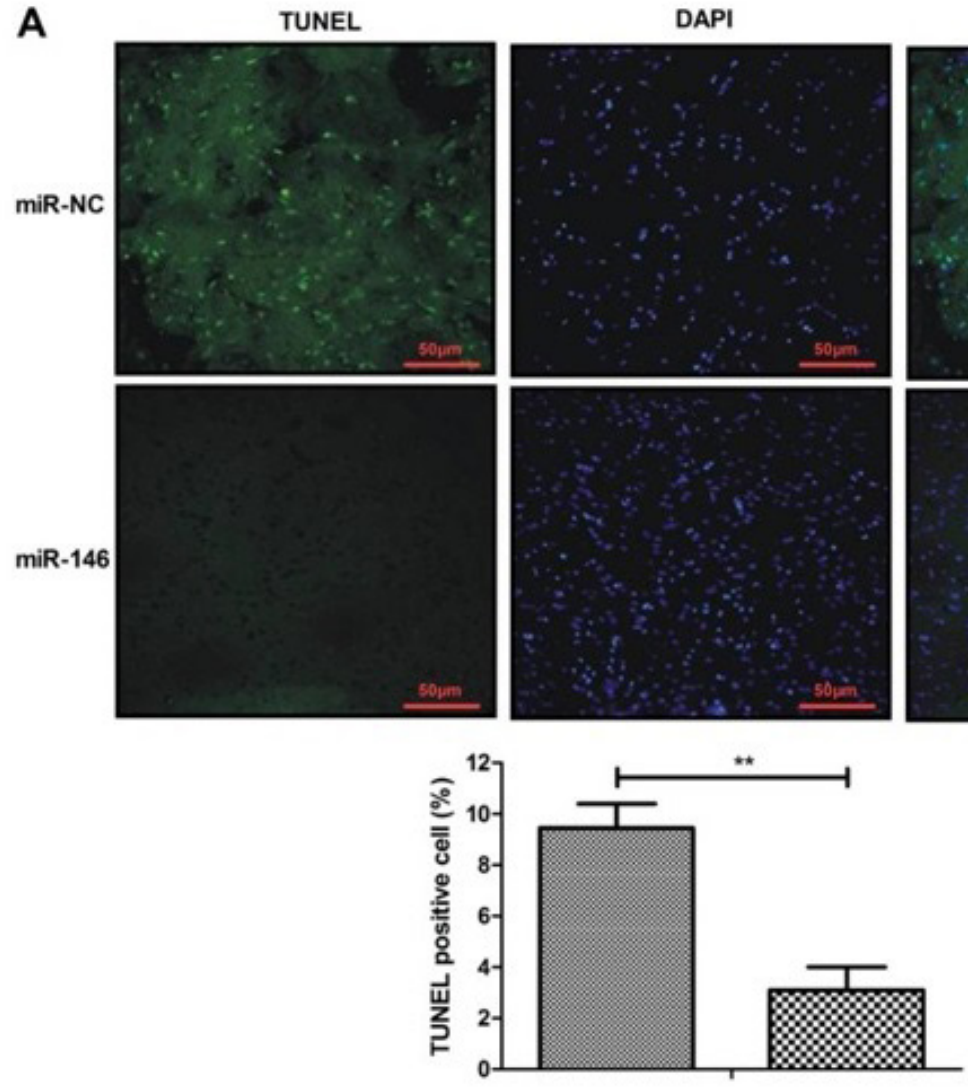

MERGE
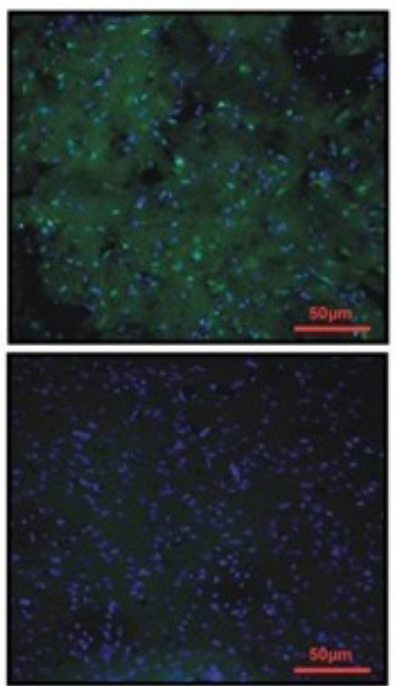

miR-NC

$\$ \mathbf{m i R}-146$
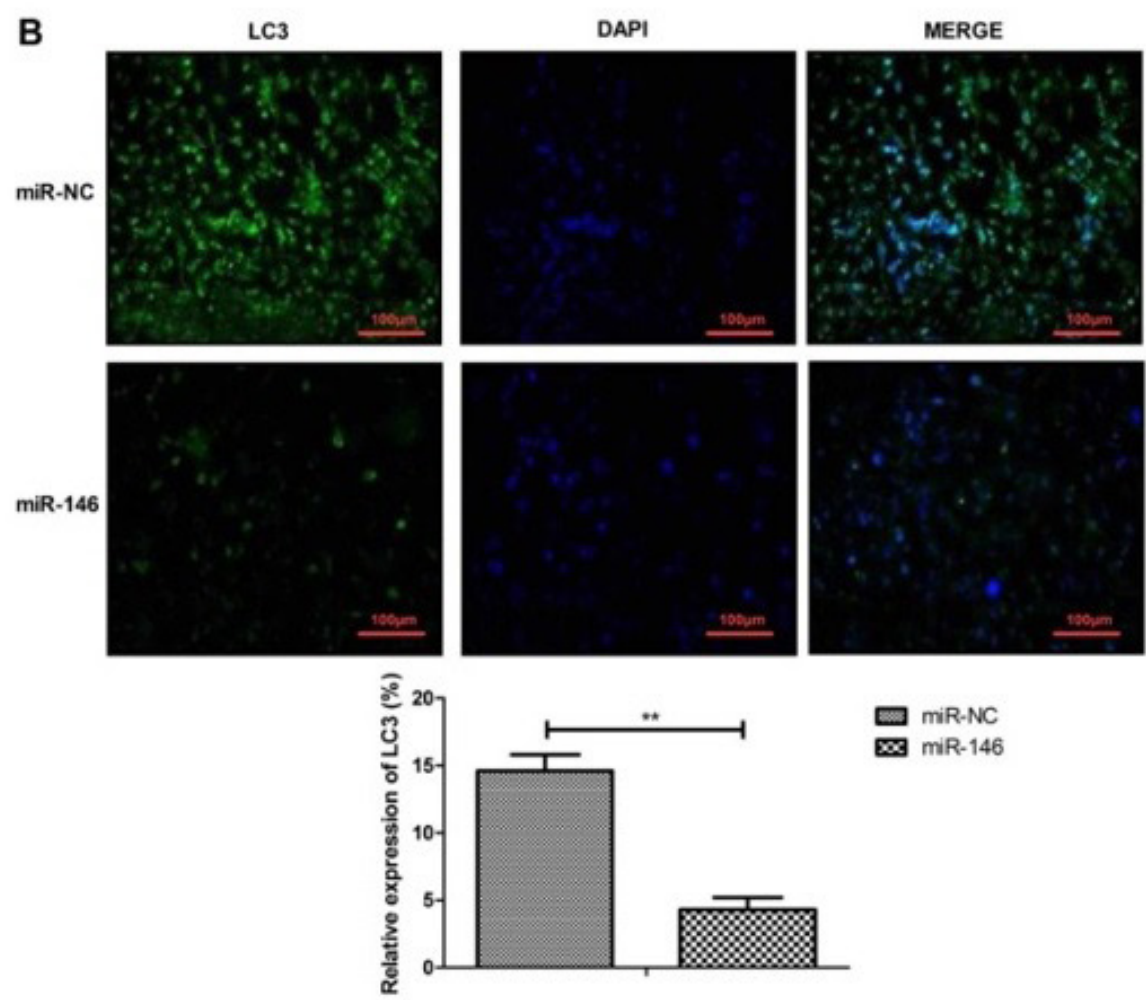

$\infty \mathbf{m i R}-146$

Figure 4. miR-146 directly modulated NF- $\kappa$ B expression in neuronal cell. (A) The relative luciferase activity of co-transfection with miR-146 mimics carrying the 3'UTR of NF- $\kappa$ B compared with the negative control; (B) Transfection of miR-146 decreased NF- $\kappa$ B and pNF- $\kappa$ B expression in neuronal cells. ${ }^{* *} \mathrm{P}<0.01$ compared with miR-NC group. nsP $>0.05$ compared with miR-NC group. 
A

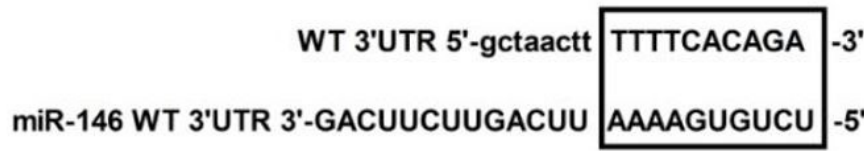

miR-146 MUT 3'UTR 3'-gctaacttttCGATAGAC-5'

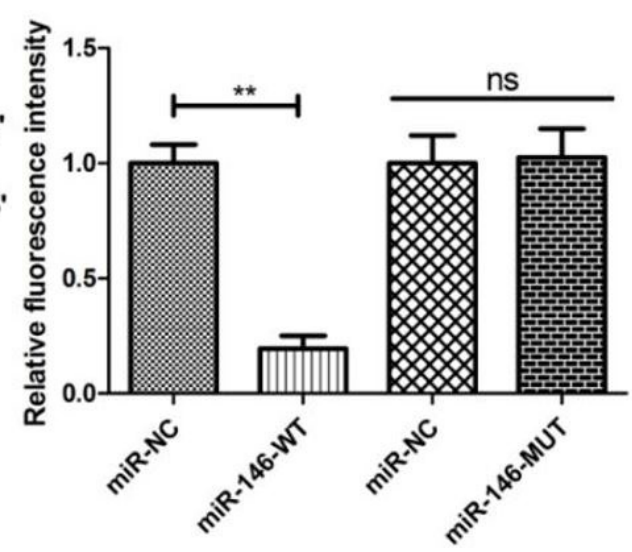

B

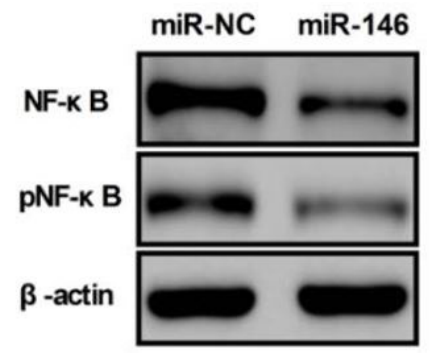

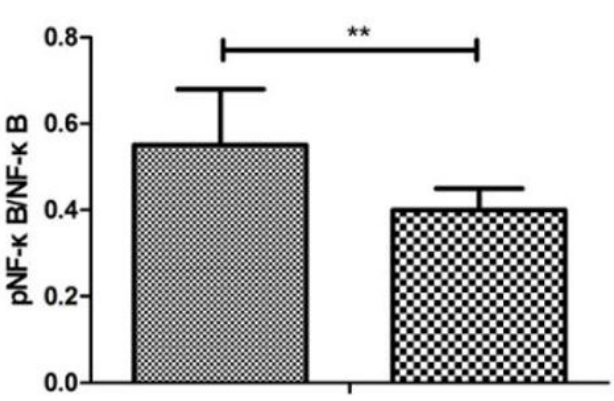

Figure 5. miR-146 activated PI3K/Akt/mTOR signaling pathway by targeting NF- $\kappa B$ gene in neuronal cells. (A) Effects of miR-146 transfection on PI3K, p-PI3K, Akt, p-Akt, mTOR and p-mTOR expression in neuronal cells; (B) Effects of inhibitor (NF-kBIR) on PI3K, Akt and mTOR expression in neuronal cells compared to control. ${ }^{*} \mathrm{P}<0.01$ compared with miR-NC group. $\mathrm{ns} \mathrm{P}>0.05$ compared with miR-NC group.

protected mice against cerebral I/R injury rat compared with the control group. In vivo findings indicated that miR-146+/+ decreased brain damage, inflammation and oxidative stress in cerebral $\mathrm{I} / \mathrm{R}$ injury rat compared to $\mathrm{I} / \mathrm{R}$ injury rat. In vitro assay demonstrated that miR-146 inhibited neuronal cell death, reduced apoptosis and autophagy in neuronal cells. Data suggest that miR-146 improves cerebral I/R injury rat via activating $\mathrm{PI} 3 \mathrm{~K} / \mathrm{Akt} / \mathrm{mTOR}$ signaling pathway by targeting NF- $\mathrm{KB}$ gene in neuronal cell.

Inflammation plays crucial role in the processes of cerebral I/R injury reducing inflammatory cytokines, such as intercellular cell adhesion molecule-1 (ICAM-1), nuclear factor-kappaB (NF-kappaB), tumor necrosis factor (TNFa), and interleukin-1 beta (IL1 $\beta$ ) in a rat model of transient global cerebral ischemia/ reperfusion attenuated cerebral ischemia/reperfusion injury (Wu et al., 2018). In the current study, miR-146 decreased serum level of IL-1 $\beta$, IL- 6 and TNF- $\alpha$ in mice model of cerebral ischemia/reperfusion injury. Inhibition of oxidative stress can protect rats against I/R injury by regulation of NOX2/NOX4 expression and exacerbates cerebral I/R injury (Lou et al., 2018). Attenuating oxidative stress contributes neuronal apoptosis in rats with focal cerebral ischemia-reperfusion injury, which may serve as a potential target for the treatment of I/R brain injury (Xia et al., 2018). This study found that miR-146+/+ increased the contents of MDA, the activity of SOD and decreased ROS in serum in I/R injury rat. Our study indicated that the mechanisms of miR-146 are associated with decreasing inflammation and enhancing oxidant defense systems in cerebral ischemia-reperfusion injury rat.

Decreasing apoptosis presents a protective effect on cerebral ischemia reperfusion injury in rats (Liu et al., 2018c). The results of in previous study indicate reducing endoplasmic reticulum stress stress-induced apoptosis is a potential novel therapeutic target for the treatment of cerebral I/R injury (Liu et al., 2018a). The results in this study demonstrated that miR-146 had protective effect on apoptosis of neuronal cell, which decreased cell apoptosis and infarct size of hippocampal CA1 pyramidal layer was shown in cerebral I/R injury mice. Data demonstrated that miR-146 decreased autophagy-related proteins LC-3, Beclin-1 and increased p62 in neuronal cells, which further explained anti-apoptotic mechanism of miR-146. Thus, miR-146 may be a promising potential therapeutic molecular for the treatment of ischemic brain injury.

Previously, suppressing the NF- $\mathrm{kB}$ signaling pathway alleviates inflammatory injury in cerebral I/R rats (Jiang et al., 2017). In addition, PI3K/Akt/mTOR signaling pathway may provide distinct cellular targets for a new generation of therapeutic agents for the treatment cerebral I/R injury (Li et al., 2015). Transfection of miR-146 decreased cerebral I/R damage, activation of NF- $\mathrm{kB}$ and excessive activation of autophagy in neuronal cells. Furthermore, a study indicates that activation of PI3K/ AKT/mTOR pathway shows a neuroprotective effect against 

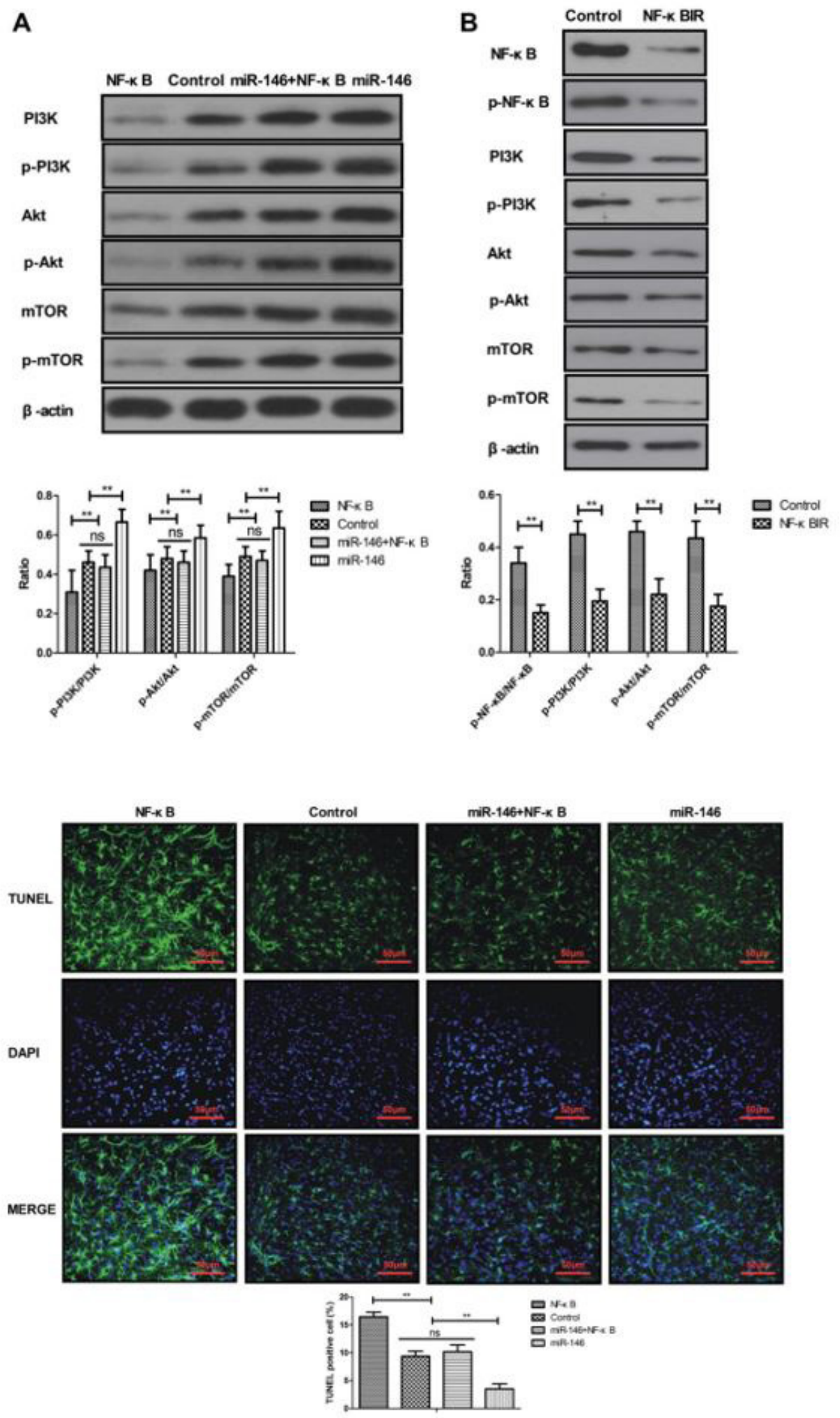

Figure 6. Effects of NF- $\kappa B$ overexpression on miR-146-decreased apoptosis of neuronal cells. Capital letters compare means between cycles in the same treatment. 
cerebral ischemia/reperfusion injury (Wan et al., 2016). Here, we reported that miR-146 directly modulated NF- $\kappa$ B expression in neuronal cells. Notably, results in the current study demonstrated that miR-146 activated PI3K/Akt/mTOR signaling pathway by targeting NF- $\kappa \mathrm{B}$ gene in neuronal cell. Further investigations are required to identify other possible mechanism of miR-146 with other signaling systems that understand the therapeutic efficacy in the pathological processes.

In conclusion, the findings of this study suggest that miR-146 provides neuroprotective effects against cerebral I/R injury, which is partially mediated by activation of NF- $\mathrm{kB}$-mediated PI3K/AKT/ mTOR. Results regarding the miR-146-mediated inflammation, oxidative stress and apoptosis provide a new insight into and therapeutic agent for cerebral I/R injury. This study provides evidences for a potential mechanism involved in pathophysiology of cerebral I/R injury.

\section{References}

Aldakkan, A., Mansouri, A., Jaja, B. N., Alotaibi, N. M., \& MacDonald, R. L., \& Subarachnoid Hemorrhage International Trialists Collaborators. (2017). Predictors of delayed cerebral ischemia in patients with aneurysmal subarachnoid hemorrhage with asymptomatic angiographic vasospasm on admission. World Neurosurgery, 97, 199-204. http:// dx.doi.org/10.1016/j.wneu.2016.09.096. PMid:27717776.

Chang, T. C., \& Mendell, J. T. (2007). microRNAs in vertebrate physiology and human disease. Annual Review of Genomics and Human Genetics, 8(1), 215-239. http://dx.doi.org/10.1146/annurev. genom.8.080706.092351. PMid:17506656.

Du, S., Deng, Y., Yuan, H., \& Sun, Y. (2019). Safflower yellow B protects brain against cerebral ischemia reperfusion injury through AMPK/NF$\mathrm{kB}$ pathway. Evidence-based Complementary and Alternative Medicine: eCAM, 2019, 7219740. http://dx.doi.org/10.1155/2019/7219740.

Gabriel-Salazar, M., Morancho, A., Rodriguez, S., Buxó, X., García-Rodríguez, N., Colell, G., Fernandez, A., Giralt, D., Bustamante, A., Montaner, J., \& Rosell, A. (2018). Importance of angiogenin and endothelial progenitor cells after rehabilitation both in ischemic stroke patients and in a mouse model of cerebral ischemia. Frontiers in Neurology, 9, 508. http://dx.doi.org/10.3389/fneur.2018.00508. PMid:30008694.

Garcia, J. H., Wagner, S., Liu, K. F., \& Hu, X. J. (1995). Neurological deficit and extent of neuronal necrosis attributable to middle cerebral artery occlusion in rats. Statistical validation. Stroke, 26(4), 627634, discussion 635. http://dx.doi.org/10.1161/01.STR.26.4.627. PMid:7709410.

Glinsky, G. V. (2009). Human genome connectivity code links diseaseassociated SNPs, microRNAs and pyknons. Cell Cycle (Georgetown, Tex.), 8(6), 925-930. http://dx.doi.org/10.4161/cc.8.6.7937. PMid:19229130.

Hu, J., \& Shen, W. (2019). microRNA-196a attenuates ischemic brain injury in rats by directly targeting high mobility group A1. Experimental and Therapeutic Medicine, 17(3), 1579-1586. http:// dx.doi.org/10.3892/etm.2019.7152. PMid:30783424.

Huang, R., Ma, J., Niu, B., Li, J., Chang, J., Zhang, Y., Liu, P., \& Luan, X. (2019). MiR-34b protects against focal cerebral Ischemia-Reperfusion (I/R) injury in rat by Targeting Keap1. Journal of Stroke and Cerebrovascular Diseases: the Official Journal of National Stroke Association, 28(1), 1-9. http://dx.doi.org/10.1016/j.jstrokecerebrovasdis.2018.08.023.

Huang, Y., Wang, H., Wang, Y., Peng, X., Li, J., Gu, W., He, T., \& Chen, M. (2018). Regulation and mechanism of miR-146 on renal ischemia reperfusion injury. Die Pharmazie, 73(1), 29-34. http://dx.doi. org/10.1691/ph.2018.7776. PMid:29441948.
Jia, D., Han, B., Yang, S., \& Zhao, J. (2014). Anemonin alleviates nerve injury after cerebral ischemia and reperfusion $(\mathrm{I} / \mathrm{R})$ in rats by improving antioxidant activities and inhibiting apoptosis pathway. Journal of Molecular Neuroscience, 53(2), 271-279. http://dx.doi.org/10.1007/s12031-013-0217-z.

Jiang, J., Luo, Y., Qin, W., Ma, H., Li, Q., Zhan, J., \& Zhang, Y. (2017). Electroacupuncture suppresses the NF- $\kappa \mathrm{B}$ signaling pathway by upregulating cylindromatosis to alleviate inflammatory injury in cerebral ischemia/reperfusion rats. Frontiers in Molecular Neuroscience, 10, 363. http://dx.doi.org/10.3389/fnmol.2017.00363. PMid:29163038.

Li, M., Marin-Muller, C., Bharadwaj, U., Chow, K. H., Yao, Q., \& Chen, C. (2009). MicroRNAs: control and loss of control in human physiology and disease. World Journal of Surgery, 33(4), 667-684. http://dx.doi. org/10.1007/s00268-008-9836-x. PMid:19030926.

Li, W., Yang, Y., Hu, Z., Ling, S., \& Fang, M. (2015). Neuroprotective effects of DAHP and Triptolide in focal cerebral ischemia via apoptosis inhibition and PI3K/Akt/mTOR pathway activation. Frontiers in Neuroanatomy, 9, 48. http://dx.doi.org/10.3389/fnana.2015.00048. PMid:25954164.

Liang, L., Wang, J., Yuan, Y., Zhang, Y., Liu, H., Wu, C., \& Yan, Y. (2018). MicRNA-320 facilitates the brain parenchyma injury via regulating IGF-1 during cerebral I/R injury in mice. Biomedicine \& Pharmacotherapy, 102, 86-93. http://dx.doi.org/10.1016/j.biopha.2018.03.036.

Liu, C., Fu, Q., Mu, R., Wang, F., Zhou, C., Zhang, L., Yu, B., Zhang, Y., Fang, T., \& Tian, F. (2018a). Dexmedetomidine alleviates cerebral ischemia-reperfusion injury by inhibiting endoplasmic reticulum stress dependent apoptosis through the PERK-CHOP-Caspase-11 pathway. Brain Research, 1701, 246-254. http://dx.doi.org/10.1016/j. brainres.2018.09.007. PMid:30201260.

Liu, G., Guo, Z., Sun, X., Chai, W., Qi, L., Li, H., Zheng, J., Guo, T., He, Z., Zhang, X., Zhu, J., \& Luo, Y. (2018b). Monitoring of the effect of cerebral autoregulation on delayed cerebral ischemia in patients with aneurysmal subarachnoid hemorrhage. World Neurosurgery, 118, e269-e275. http://dx.doi.org/10.1016/j.wneu.2018.06.170. PMid:29969743.

Liu, T., Song, F., Lu, D. Y., Dong, L., Wu, Q., Liu, Z. Y., Li, Y. J., \& Wang, A. M. (2018c). Anti-oxidation and anti-apoptosis mechanism of Xinshao formula on cerebral ischemia reperfusion injury. Zhongguo Zhong yao za zhi = Zhongguo zhongyao zazhi = China journal of Chinese materia medica, 43(17), 3519-3524. http://dx.doi.org/10.19540/j. cnki.cjcmm.20180427.002. PMid:30347921.

Lorenzen, J. M., Batkai, S., \& Thum, T. (2013). Regulation of cardiac and renal ischemia-reperfusion injury by microRNAs. Free Radical Biology \& Medicine, 64, 78-84. http://dx.doi.org/10.1016/j. freeradbiomed.2013.06.044. PMid:23845966.

Lou, Z., Wang, A. P., Duan, X. M., Hu, G. H., Song, G. L., Zuo, M. L., \& Yang, Z. B. (2018). Upregulation of NOX2 and NOX4 Mediated by TGF- $\beta$ Signaling Pathway Exacerbates Cerebral Ischemia/Reperfusion Oxidative Stress Injury. Cellular Physiology and Biochemistry, 46(5), 2103-2113. http://dx.doi.org/10.1159/000489450. PMid:29723859.

Müller, M. D., Ahlhelm, F. J., von Hessling, A., Doig, D., Nederkoorn, P. J., Macdonald, S., Lyrer, P. A., van der Lugt, A., Hendrikse, J., Stippich, C., van der Worp, H. B., Richards, T., Brown, M. M., Engelter, S. T., \& Bonati, L. H. (2017). Vascular anatomy predicts the risk of cerebral ischemia in patients randomized to carotid stenting versus endarterectomy. Stroke, 48(5), 1285-1292. http://dx.doi.org/10.1161/ STROKEAHA.116.014612. PMid:28400487.

Pala, A., Schneider, M., Brand, C., Pedro, M. T., Özpeynirci, Y., Schmitz, B., Wirtz, C. R., Kapapa, T., König, R., \& Braun, M. (2019). The evolution of invasive cerebral vasospasm treatment in patients with spontaneous subarachnoid hemorrhage and delayed cerebral ischemia-continuous selective intracarotid nimodipine therapy in awake patients without sedation. Neurosurgical Review, 42(2), 463469. http://dx.doi.org/10.1007/s10143-018-0986-5. PMid:29804157. 
Pan, Y. B., Sun, Z. L., \& Feng, D. F. (2017). The role of MicroRNA in traumatic brain injury. Neuroscience, 367, 189-199. http://dx.doi. org/10.1016/j.neuroscience.2017.10.046. PMid:29113926.

Tao, Z., Zhao, H., Wang, R., Liu, P., Yan, F., Zhang, C., Ji, X., \& Luo, Y. (2015). Neuroprotective effect of microRNA-99a against focal cerebral ischemia-reperfusion injury in mice. Journal of the Neurological Sciences, 355(1-2), 113-119. http://dx.doi.org/10.1016/j. jns.2015.05.036. PMid:26055311.

Von der Brelie, C., Seifert, M., Rot, S., Tittel, A., Sanft, C., Meier, U., \& Lemcke, J. (2017). Sedation of patients with acute aneurysmal subarachnoid hemorrhage with ketamine is safe and might influence the occurrence of cerebral infarctions associated with delayed cerebral ischemia. World Neurosurgery, 97, 374-382. http://dx.doi. org/10.1016/j.wneu.2016.09.121. PMid:27742511.

Wan, D., Zhou, Y., Wang, K., Hou, Y., Hou, R., \& Ye, X. (2016). Resveratrol provides neuroprotection by inhibiting phosphodiesterases and regulating the cAMP/AMPK/SIRT1 pathway after stroke in rats. Brain Research Bulletin, 121, 255-262. http://dx.doi.org/10.1016/j. brainresbull.2016.02.011. PMid:26876758.

Weiss, J. B., Eisenhardt, S. U., Stark, G. B., Bode, C., Moser, M., \& Grundmann, S. (2012). Micrornas in ischemia-reperfusion injury. American Journal of Cardiovascular Disease, 2(3), 237-247. PMid:22937493.

Wu, H., Tang, C., Tai, L. W., Yao, W., Guo, P., Hong, J., Yang, X., Li, X., Jin, Z., Ke, J., \& Wang, Y. (2018). Flurbiprofen axetil attenuates cerebral ischemia/reperfusion injury by reducing inflammation in a rat model of transient global cerebral ischemia/reperfusion. Bioscience Reports, 38(4), BSR20171562. http://dx.doi.org/10.1042/ BSR20171562. PMid:29540536.
Xia, D., Zhang, Z., \& Zhao, Y. (2018). Acteoside attenuates oxidative stress and neuronal apoptosis in rats with focal cerebral ischemiareperfusion injury. Biological \& Pharmaceutical Bulletin, 41(11), 1645-1651. http://dx.doi.org/10.1248/bpb.b18-00210. PMid:30381663.

Yang, B. F., Lu, Y. J., \& Wang, Z. G. (2009). MicroRNAs and apoptosis: implications in the molecular therapy of human disease. Clinical and Experimental Pharmacology \& Physiology, 36(10), 951-960. http:// dx.doi.org/10.1111/j.1440-1681.2009.05245.x. PMid:19566826.

Yang, G., Wang, N., Seto, S. W., Chang, D., \& Liang, H. (2018). Hydroxysafflor yellow a protects brain microvascular endothelial cells against oxygen glucose deprivation/reoxygenation injury: Involvement of inhibiting autophagy via class I PI3K/Akt/mTOR signaling pathway. Brain Research Bulletin, 140, 243-257. http:// dx.doi.org/10.1016/j.brainresbull.2018.05.011. PMid:29775658.

Yang, Y., Liu, P., Chen, L., Liu, Z., Zhang, H., Wang, J., Sun, X., Zhong, W., Wang, N., Tian, K., \& Zhao, J. (2013). Therapeutic effect of Ginkgo biloba polysaccharide in rats with focal cerebral ischemia/ reperfusion (I/R) injury. Carbohydrate Polymers, 98(2), 1383-1388. http://dx.doi.org/10.1016/j.carbpol.2013.07.045. PMid:24053818.

Yao, X., Wang, Y., \& Zhang, D. (2018). microRNA-21 confers neuroprotection against cerebral ischemia-reperfusion injury and alleviates blood-brain barrier disruption in rats via the MAPK signaling pathway. Journal of Molecular Neuroscience, 65(1), 43-53. http://dx.doi.org/10.1007/s12031-018-1067-5.

Zhai, F., Zhang, X., Guan, Y., Yang, X., Li, Y., Song, G., \& Guan, L. (2012). Expression profiles of microRNAs after focal cerebral ischemia/ reperfusion injury in rats. Neural Regeneration Research, 7(12), 917-923. http://dx.doi.org/10.3969/j.issn.1673-5374.2012.12.007. PMid:25722676. 